\title{
The use of infrared thermography for welfare assessment during the application of ear tags to lambs
}

\author{
Murat Karakuş ${ }^{1}$ and Ferda Karakuş ${ }^{2}$ \\ ${ }^{1}$ Van Directorate of Provincial Food Agriculture and Livestock, Van, Turkey \\ ${ }^{2}$ Department of Animal Science, Faculty of Agriculture, Yuzuncu Yil University, Van, Turkey \\ Correspondence to: Ferda Karakuş (fkarakus@yyu.edu.tr)
}

Received: 4 April 2017 - Revised: 20 June 2017 - Accepted: 24 July 201 - Published: 31 August 2017

\begin{abstract}
The aim of this study was to determine the effect of metal-tipped, plastic-tipped, and electronic ear tags on the likelihood of infection using infrared thermography and to evaluate the effect on welfare by examining the behavioral responses of the lambs. Ninety lambs with an average age of 6 months were used in this study. Before the application of the ear tags, infrared images of the right and left ears of the lambs were taken with the thermal camera and the infrared temperatures were recorded. Measurements were repeated on days $1,4,10$, and 30 after the ear tag application. The mean of infrared ear temperatures on days $0,1,4,10$, and 30 were found to be $14.60,23.20,23.77,20.36$, and $17.61^{\circ} \mathrm{C}$ for the metal-tipped ear tag group; $15.69,21.50,20.42,18.00$, and $16.39^{\circ} \mathrm{C}$ for the plastic-tipped ear tag group; and $15.17,29.47,27.49,25.93$, and $20.61^{\circ} \mathrm{C}$ for the electronic ear tag group. The infrared temperatures on days 1,4 , and 10 in the control and experimental groups were significantly different from each other $(P<0.001)$. The plastic-tipped ear tags caused fewer problems and are preferred to the traditional ear tags with metal tips. The electronic ear tags caused more inflammatory reactions compared to metal- or plastic-tipped ear tags. The infrared thermography method may be used as a useful tool in the early detection of the inflammatory reactions and infections caused by the application of ear tags.
\end{abstract}

\section{Introduction}

Today, there is an increasing consumer demand for "clean, green, and ethical" animal production (Martin and Kadokawa, 2006). The goal of the "clean" approach is to minimize or eliminate the use of drugs, chemicals, and hormones. "Green" involves doing the least damage to the environment. However, the "ethical" aspect involving concerns for animal welfare is an important issue for livestock management since consumers want to consume products obtained from animals that have been managed humanely (Martin and Kadokawa, 2006; Martin, 2009).

The control of pain and stress during routine husbandry procedures commonly used on farms is crucially important in terms of animal welfare. However, the treatment of pain has been traditionally overlooked in farm animals compared to companion animals (Stewart, 2008). Ear tagging is one of the identification procedures most commonly performed on farm animals for routine on-farm management. Ear tags may result in an inflammatory response due to the wound created when they are inserted into the ear. Ear wounds should be considered in terms of ear tag loss and welfare implications, since retagging an animal will result in increased cost and animal stress (Karakuş et al., 2015b). Depending on the pain-induced stress, the feed consumption of the animals and the rate of growth in young animals is adversely affected (Leslie et al., 2010). Therefore, early detection and treatment of inflammation or ear tissue reaction is economically and strategically advantageous (Karakuş et al., 2015b). Edwards et al. (2001) indicated that the insertion of ear tags resulted in an inflammatory response in ewes and lambs.

An animal in pain shows some behavioral signs associated with pain. Restlessness, lameness, self-mutilation, and vocalization, as well as changes in eye expressions, appetite, temperament, and physical activity are the most striking signs that an animal is in pain. Observation of behavior is the most common, useful, and noninvasive parameter used for recognizing pain in animals due to the difficulties of measuring 
pain through physiological indicators, such as food and water consumption, respiratory rate, heart rate, blood pressure, and endocrine responses (Young, 2006).

Grant (2004), who examined the behavioral responses of lambs following a range of commonly used husbandry procedures, observed kicking, tail wagging, jumping, restlessness, and vocalization behavior only in lambs that had been ear tagged. Ear tagging was the practice to which the least reactions were observed among husbandry procedures.

The level of pain suffered by an animal can be determined by monitoring the clinical, physiological, and behavioral reactions of the animal (Antalyal1, 2007). However, the main issue in animal welfare research is the fact that most of the existing methods used to measure stress and pain are invasive. Therefore, there is a lack of reliable and noninvasive tools (Stewart et al., 2008).

Infrared thermography has been used for many years to detect and measure an animal's response to stress. The hypothalamic-pituitary-adrenal (HPA) axis is activated when an animal becomes stressed, and heat is produced because of increases in catecholamines and cortisol levels in addition to blood flow responses. This response can be detected with thermal imaging systems (Church et al., 2009). Karakuş et al. (2015b) reported that infrared thermography, as a noninvasive diagnostic tool, can be used to identify lambs with inflammations caused by ear tags.

In this study, the aim was to determine the effect of metaltipped, plastic-tipped, and electronic ear tags on the likelihood of infection using infrared thermography and to evaluate the effect on welfare by examining the behavioral responses of the lambs.

\section{Material and methods}

\subsection{Animals and data collection}

This study does not require the approval of Animal Research Ethic Committee since it is within the scope of applications that are used for identifying individual animals (Yuzuncu Yil University (Turkey) Animal Research Local Ethic Committee decision number: 2015/12).

Ninety Akkaraman lambs with an average age of 6 months were used in this study. The lambs were managed under extensive conditions and identified by electronic ear (e-ET) tags, metal-tipped (mt-ET), or plastic-tipped (pt-ET) ear tags, officially approved by the Turkish Republic's Ministry of Food, Agriculture and Livestock. Electronic ear tags containing an FDX-B (full-duplex B) transponder and working at an activation frequency of $134.2 \mathrm{kHz}$ in accordance with ISO 11784 and 11785 standards (ISO, 1996a, b) were used. The button-type electronic ear tag had a weight of $6.6 \mathrm{~g}$ and a diameter of $27.5 \mathrm{~mm}$.

The total weight of a metal-tipped ear tag was $4 \mathrm{~g}$, and the dimensions for female and male pieces were $38 \times 40$ and $38 \times 35 \mathrm{~mm}$, respectively. Plastic-tipped ear tags weighed

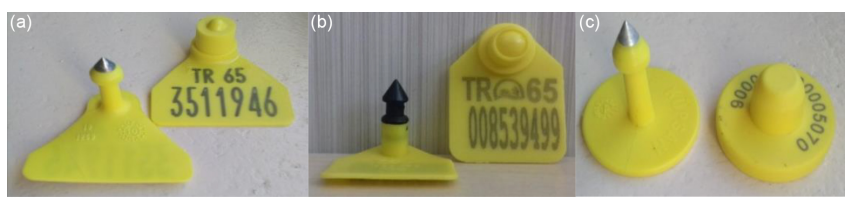

Figure 1. Metal-tipped (a), plastic-tipped (b), and electronic ear tag (c) applied in the lambs.

$4.6 \mathrm{~g}$, and the dimensions for female and male pieces were $31 \times 41$ and $31 \times 34 \mathrm{~mm}$, respectively. All the ear tags were tamper proof, yellow in color, and laser printed (Fig. 1). Infrared images of the ear tissue of the lambs were obtained using an FLIR E50 (FLIR Systems, Inc.) thermal imaging camera.

At the beginning of the experiment, the lambs were randomly divided into three groups per ear tag type. The mt-ET were attached to the right ear and the e-ET were attached to the left ear of lambs in the first group $(n=30)$. The pt-ET were attached to the right ear and the e-ET were attached to the left ear of lambs in the second group $(n=30)$. A third group of lambs without ear tags was used as a control group.

Before the application of the ear tags, infrared images of the right and left ears of the lambs were taken with the thermal camera and the infrared temperatures were recorded. The thermal camera taking infrared images was positioned about $0.5 \mathrm{~m}$ from the head of the animal. The temperature and relative humidity in the barn were recorded by using a data logger on each day of the experiment, and the camera was calibrated according to those values.

The applicator and ear tags were immersed in an antiseptic solution before tagging any of the lambs. The lambs in the control group were not treated. The behavior of the lambs was monitored for $3 \mathrm{~min}$ following the tagging, and the behavioral criteria reported by Molony et al. (2002) and Grant (2004) were used to assess the pain.

The first day after tagging, the infrared images of both ears of all animals, including the control group, were taken again. Measurements were repeated on days 4, 10, and 30 (Figs. 2, 3, 4). Infected ears were monitored weekly until healed and any necessary treatment was performed. The live weight of the lambs was recorded using a weighing scale at the beginning and end of the experiment.

\subsection{Statistical analysis}

The effect of the type of ear tag and the measurement days of the infrared ear temperature of lambs was examined by analysis of variance. The following mathematical model was used to determine the influence of the type of ear tag.

$Y_{i j}=\mu+a_{i}+e_{i j}$

where $Y_{i j}$ is the observation value, $\mu$ the overall mean, $a_{i}$ the effect of the type of ear tag $(i=1,2,3$ : denoting metal- 


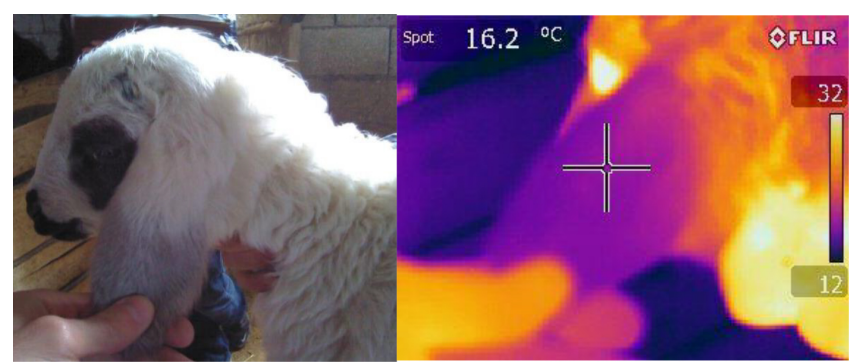

Figure 2. Infrared images of ear tissue prior to the application of ear tags in lambs (day 0).

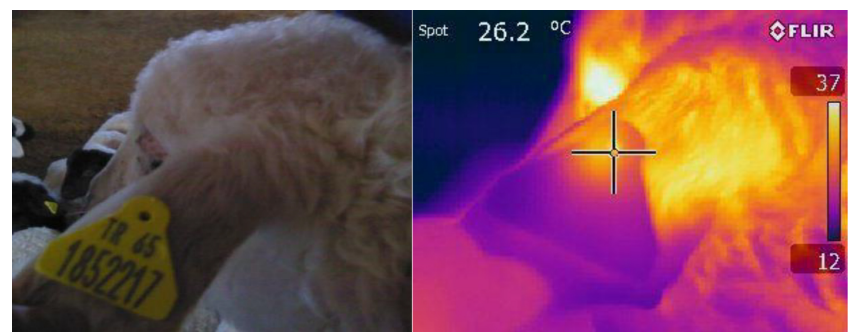

Figure 3. Infrared images of ear tissue after the application of metal-tipped ear tags in lambs (day 1).

tipped, plastic-tipped, and electronic ear tags), and $e_{i j}$ the random error.

The following mathematical model was used to determine the influence of measurement days:

$Y_{i j}=\mu+a_{i}+e_{i j}$,

where $Y_{i j}$ is the observation value, $\mu$ the overall mean, $a_{i}$ the effect of the measurement day $(i=1,2,3,4,5$ : denoting days $0,1,4,10$, and 30 ), and $e_{i j}$ the random error.

The chi-square test was used to evaluate the behavioral criteria used to assess pain in the lambs. All analyses were performed using SAS (2005) statistical software.

\section{Results}

Live-weight changes in the lambs at the beginning and end of the experiment are presented in Table 1 . The mean live weight of the lambs at the beginning of the experiment was $29.77 \mathrm{~kg}$ for the mt-ET group, $34.58 \mathrm{~kg}$ for the pt-ET group, and $30.33 \mathrm{~kg}$ for the e-ET group. Lambs in the pt-ET group were significantly heavier $(P<0.01)$ than lambs in the mt-ET and control groups. At the end of the experiment, the mean live weight of the lambs was found to be $46.30 \mathrm{~kg}$ for the mtET group, $49.97 \mathrm{~kg}$ for the pt-ET group, and $48.07 \mathrm{~kg}$ for the e-ET group. There was a significant difference between the pt-ET and mt-ET groups for final live weight $(P<0.05)$.

The infrared ear temperatures of the lambs in the experiment and control groups for days $0,1,4,10$, and 30 are given in Table 2. The temperature values on day 0 for lambs with

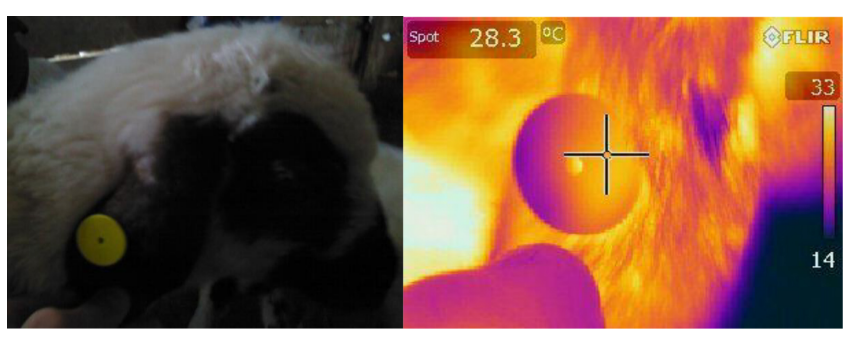

Figure 4. Infrared images of ear tissue after the application of electronic ear tags in lambs (day 1).

mt-ET, pt-ET, e-ET, and the control group were 14.60, 15.69, 15.17 , and $15.52^{\circ} \mathrm{C}$, respectively $(P<0.05)$. On day 1 after the application of the ear tags, the infrared temperature difference was $8.60^{\circ} \mathrm{C}$ in the mt-ET group, $5.81^{\circ} \mathrm{C}$ in the pt-ET group, and $14.30^{\circ} \mathrm{C}$ in the e-ET group. Differences between the infrared ear temperatures of the control and experimental groups were found to be very significant $(P<0.001)$.

In addition to the control group, the temperature values for the pt-ET and e-ET groups decreased on day 4, whereas no change was observed in the mt-ET group. The differences observed between the groups on day 4 were very significant $(P<0.001)$. On day 10 of the ear tag application, the infrared temperatures continued to decrease in all experimental groups. The temperature values on day 10 in the control and experimental groups were significantly different from each other $(P<0.001)$.

On day 30 of the ear tag application, the infrared ear temperatures of the lambs with e-ET were significantly higher than those of the other groups $(P<0.001)$. The mean infrared temperature in the mt-ET group was also found to be higher than that of the lambs in the control group $(P<0.001)$.

Behavioral criteria used to assess pain in lambs with mt$\mathrm{ET}+\mathrm{e}-\mathrm{ET}$ and pt-ET $+\mathrm{e}-\mathrm{ET}$ are presented in Table 3. In this study, $63.33 \%$ of lambs with mt-ET + e-ET and $56.67 \%$ of lambs with pt-ET + e-ET showed horizontal head shaking behavior. The second most commonly observed type of behavior was when lambs stamped their feet (40.00 and $33.33 \%$ ). The percentage of lambs that made high-pitched sounds during the application of the ear tags was $33.33 \%$ in the mt-ET + e-ET group and $26.67 \%$ in the pt-ET + e-ET group. The number of lambs showing jumping behavior was determined to be 20.00 and $30.00 \%$ in both groups.

Also, $16.67 \%$ of the lambs in the mt-ET + e-ET group and $13.33 \%$ of the lambs in the pt-ET + e-ET group showed trembling behavior. The number of lambs showing ear scratching and kneeling behavior was similar in the mtET + e-ET group at $10 \%$, whereas it was found to be 16.67 and $13.33 \%$, respectively, in the pt-ET + e-ET group. Furthermore, $6.67 \%$ of the lambs in the mt-ET + e-ET group and $13.33 \%$ of the lambs in the pt-ET + e-ET group showed lying behavior. The number showing normal standing, walk- 
Table 1. Least-squares means ( \pm SE) for the live weight of the lambs in the control and experimental groups $(\mathrm{kg})$.

\begin{tabular}{|c|c|c|c|c|}
\hline \multirow[t]{2}{*}{$\begin{array}{l}\text { Experimental } \\
\text { groups }\end{array}$} & \multicolumn{2}{|c|}{$\begin{array}{c}\text { Live weight at the beginning } \\
\text { of the experiment }\end{array}$} & \multicolumn{2}{|c|}{$\begin{array}{l}\text { Live weight at the end } \\
\text { of the experiment }\end{array}$} \\
\hline & $n$ & $\bar{x} \pm S_{\bar{x}}$ & $n$ & $\bar{x} \pm S_{\bar{x}}$ \\
\hline & & $* *$ & & $*$ \\
\hline $\mathrm{mt}-\mathrm{ET}+\mathrm{e}-\mathrm{ET}$ & 30 & $29.77 \pm 1.06^{\mathrm{b}}$ & 30 & $46.30 \pm 0.96^{\mathrm{b}}$ \\
\hline pt-ET + e-ET & 30 & $34.58 \pm 0.92^{\mathrm{a}}$ & 30 & $49.97 \pm 0.72^{\mathrm{a}}$ \\
\hline Control & 30 & $30.33 \pm 0.94^{b}$ & 30 & $48.07 \pm 1.05^{\mathrm{ab}}$ \\
\hline
\end{tabular}

mt-ET: metal-tipped ear tags; pt-ET: plastic-tipped ear tags; e-ET: electronic ear tags. ${ }^{\text {a, }}$ b Means values with different letters in the same column are significant. ${ }^{*} P<0.05,{ }^{* *} P<0.01$.

Table 2. Least-squares means $( \pm \mathrm{SE})$ for the infrared ear temperatures of lambs on days $0,1,4,10$, and $30\left({ }^{\circ} \mathrm{C}\right)$.

\begin{tabular}{|c|c|c|c|c|c|c|c|c|c|}
\hline \multirow[t]{2}{*}{ Measurement days } & \multicolumn{2}{|r|}{ mt-ET } & \multicolumn{2}{|r|}{ pt-ET } & \multicolumn{2}{|r|}{ e-ET } & \multicolumn{2}{|r|}{ Control } & \multirow[t]{2}{*}{$P$ value } \\
\hline & $n$ & $\bar{x} \pm S_{\bar{x}}$ & $n$ & $\bar{x} \pm S_{\bar{x}}$ & $n$ & $\bar{x} \pm S_{\bar{x}}$ & $n$ & $\bar{x} \pm S_{\bar{x}}$ & \\
\hline 0 & 30 & $14.60 \pm 0.28^{\mathrm{a}}$ & 30 & $15.69 \pm 0.21^{b}$ & 60 & $15.17 \pm 0.19^{\mathrm{ab}}$ & 30 & $15.52 \pm 0.21^{\mathrm{b}}$ & $*$ \\
\hline 1 & 30 & $23.20 \pm 0.51^{\mathrm{c}}$ & 30 & $21.50 \pm 0.49^{b}$ & 60 & $29.47 \pm 0.48^{\mathrm{d}}$ & 30 & $16.39 \pm 0.15^{\mathrm{a}}$ & $* * *$ \\
\hline 4 & 30 & $23.77 \pm 0.60^{\mathrm{c}}$ & 30 & $20.42 \pm 0.40^{\mathrm{b}}$ & 60 & $27.49 \pm 0.45^{\mathrm{d}}$ & 30 & $14.88 \pm 0.11^{\mathrm{a}}$ & $* * *$ \\
\hline 10 & 30 & $20.36 \pm 0.52^{c}$ & 30 & $18.00 \pm 0.41^{\mathrm{b}}$ & 60 & $25.93 \pm 0.50^{\mathrm{d}}$ & 30 & $15.40 \pm 0.13^{\mathrm{a}}$ & $* * *$ \\
\hline 30 & 30 & $17.61 \pm 0.51^{\mathrm{b}}$ & 30 & $16.39 \pm 0.35^{\mathrm{ab}}$ & 60 & $20.61 \pm 0.46^{\mathrm{c}}$ & 30 & $15.39 \pm 0.19^{\mathrm{a}}$ & $* * *$ \\
\hline
\end{tabular}

mt-ET: metal-tipped ear tags; pt-ET: plastic-tipped ear tags; e-ET: electronic ear tags. ${ }^{\text {a, }}$, c, d: means values with different letters in the same row are significant. * $P<0.05,{ }^{* * *} P<0.001$.

Table 3. Behavioral criteria used to assess pain in lambs with metaltipped + electronic and plastic-tipped + electronic ear tags.

\begin{tabular}{lrr|rr}
\hline Pain-related behavior & mt-ET + e-ET & pt-ET + e-ET \\
\cline { 2 - 5 } & $n$ & $\%$ & $n$ & $\%$ \\
\hline Head shaking & 19 & 63.33 & 17 & 56.67 \\
Ear scratching & 3 & 10.00 & 5 & 16.67 \\
Tail wagging & 0 & 0 & 0 & 0 \\
Vocalization & 10 & 33.33 & 8 & 26.67 \\
Lip biting & 0 & 0 & 0 & 0 \\
Trembling & 5 & 16.67 & 4 & 13.33 \\
Foot stamping & 12 & 40.00 & 10 & 33.33 \\
Kicking & 0 & 0 & 0 & 0 \\
Jumping & 6 & 20.00 & 9 & 30.00 \\
Kneeling & 3 & 10.00 & 4 & 13.33 \\
Lateral lying & 2 & 6.67 & 4 & 13.33 \\
Statue standing (for at least 10 s) & 0 & 0 & 0 & 0 \\
Normal standing & 20 & 66.67 & 18 & 60.00 \\
\hline mt-ET: metal-tipped ear tags; pt-ET: plastic-tipped ear tags; e-ET: electronic ear tags.
\end{tabular}

ing, and playing behavior following the application of the ear tags was determined to be 66.67 and $60.0 \%$ in both groups.

\section{Discussion}

Live weights of the lambs for determining the effect of ear tag application on animal welfare were determined at the beginning and end of the experiment. Changes in live weights during the experiment were $16.53 \mathrm{~kg}$ for the mt-ET group,
$15.39 \mathrm{~kg}$ for the pt-ET group, and $17.74 \mathrm{~kg}$ for the e-ET group. Although there was no statistically significant difference, the lambs of the control group gained more weight than those in the experiment groups. The rate of growth of lambs may be adversely affected by the application of ear tags.

Changes in animals due to internal and external factors cause inflammatory reactions that are a strong response resulting from natural and acquired immunity (Sevgisunar and Şahinduran, 2014). The ranking between the experimental groups for all measurement days in terms of infrared temperature increase indicating an inflammatory reaction, which is the response of the ear to the ear tag application, was found to be e-ET >mt-ET > pt-ET (Fig. 5). Kitagaki and Shibuya (2004) compared plastic and metal ear tags in terms of tissue reaction, reporting that plastic ear tags were more reliable than metal ear tags due to a lower rate of the tag falling off and less tissue damage.

There are individual differences in the tissue response to the inflammatory reaction caused by the application of ear tags. Where there is a temperature difference between the symmetrical regions of the body, a change of $10^{\circ} \mathrm{C}$ is required to indicate the presence of a significant change (Düzgün and Or, 2009).

Ear tag application had no adverse effect on the welfare of the lambs in the mt-ET group except for one lamb (3.3\%) that developed an infection. Infections occurred in the form of ear swelling, irritation under the ear tags, inflammation, and feelings of discomfort or pain when touched. The num- 


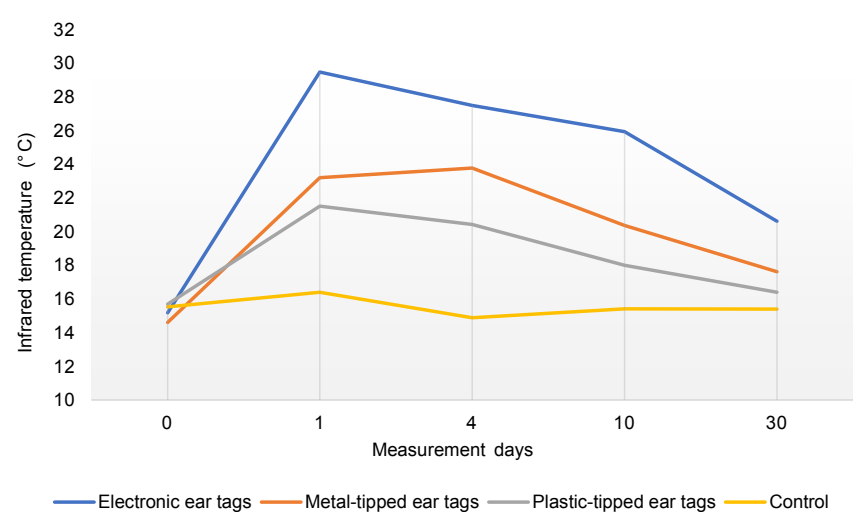

Figure 5. Comparison of the infrared ear temperature of the experimental and control group of lambs according to the measurement days.

ber of infected ears caused by metal-tipped ear tags is similar to the value of $3.3 \%$ reported by Carne et al. (2009). On the other hand, this value is lower than the $7.4 \%$ average value reported by Thomas et al. (2006) for five different types of electronic ear tags in ewes, the 80 and $50 \%$ values reported by Karakus et al. (2015b), respectively, for electronic and official plastic ear tags (metal-tipped) in lambs, and the 17.6 and $45.9 \%$ infected ear values also reported by Karakuş et al. (2016) for, respectively, metal-tipped and electronic ear tags in goat kids.

In six lambs in the pt-ET group, the ear tags had no negative effect on the welfare of the lambs. Also, none of the lambs with pt-ET developed ear infections. In contrast, 8 out of 60 lambs with e-ET (13.3\%) had infections. The number of infected ears caused by e-ET is higher than that reported by Thomas et al. (2006) and Carne et al. (2009) but lower than that reported by Karakuş et al. (2015b, 2016).

Of the ear tags applied to the lambs, only one of the lambs with an electronic ear tag $(1.7 \%)$ had bleeding, and the bleeding stopped within a few minutes. Carne et al. (2009) reported three $(3.3 \%)$ cases of extreme bleeding in 92 electronic ear tag applications. On the other hand, Kowalski et al. (2014) observed bleeding in one goat only when using large-type plastic ear tags. The tagging site on the animal's ear as well as ear tag type is significantly associated with the retention of ear tags and the severity of ear lesions. Avoiding the main veins in the ear, ear tags should be applied to a site that cannot damage the ear or cause too much ear tag loss (Karakus et al., 2015a).

The formation of a significant inflammatory reaction in the tissue reduces the resistance of the wound to infection and delays the onset of the healing process (Karasu and Bakır, 2006). In this study, all of the infected ears were completely healed by 6 weeks after the ear tags were attached. This finding is better in comparison to Carne et al. (2009), who reported that $90.2 \%$ of the infected ears recovered completely after 2 months, and in comparison to Karakuş et al. (2016), who reported that all the infected ears recovered in 10 weeks after the ear tag application, based on the severity of the wound. On the other hand, Edwards et al. (2001) reported that all wounds recovered after week 20 following the ear tag application, except for wounds resulting from metal loop tags. The wound healing process is crucially important in order to improve ear tag retention and maintain animal welfare.

An animal's behavior may show the state of pain it is in and the severity of the pain. A variety of behavioral measures were used to quantify the effect of ear tag application on the welfare of lambs (Table 3). In mt-ET + e-ET group lambs, behavior observed at the highest rates following ear tag application was head shaking (63.33\%), foot stamping (40.00\%), and vocalization $(33.33 \%)$. Jumping $(20.00 \%)$, trembling $(16.67 \%)$, ear scratching $(10.00 \%)$, kneeling $(10.00 \%)$, and lateral lying $(6.67 \%)$ was observed at lower rates. On the other hand, while behavior observed at the highest rates in pt-ET + e-ET group lambs was head shaking $(56.67 \%)$ and foot stamping (33.33\%), lambs exhibited jumping (30.00\%), vocalization $(26.67 \%)$, ear scratching $(16.67 \%)$, trembling $(13.33 \%)$, kneeling $(13.33 \%)$, and lateral lying $(13.33 \%)$ at a lower rate.

Edwards et al. (2001) questioned the use of ear tags in terms of animal welfare and reported that a higher number of lambs exhibited loud bleating and head shaking behavior when the application of the ear tags caused trouble compared to when it caused less of a problem. In contrast to the findings of this study, Grant (2004) observed kicking, tail wagging, jumping, loud bleating, and restless behavior only in lambs with ear tags.

\section{Conclusions}

When the study findings are evaluated from an animal welfare viewpoint, it can be said that the plastic-tipped ear tags caused fewer problems and are preferred to the traditional ear tags with metal tips. In addition, infrared thermography can be recommended as a tool to determine this type of stress and consequently allow a better evaluation of animal welfare.

Data availability. No data sets were used in this article.

Competing interests. The authors declare that they have no conflict of interest.

Acknowledgements. This study is based on the first author's master's thesis (Karakuş, 2016). The authors also wish to thank Suna Akkol for statistical analysis support.

Edited by: Steffen Maak

Reviewed by: two anonymous referees 


\section{References}

Antalyalı, A. A.: Avrupa Birliği ve Türkiye'de Hayvan Refahı Uygulamaları, T.C. Tarım ve Köyişleri BakanlığıDı ş İlişkiler ve Avrupa Birliği Koordinasyon Dairesi Başkanlığı, AB uzmanlık tezi, T.C. Tarım ve Köyişleri BakanlığıDış İlişkiler ve Avrupa Birliği Koordinasyon Dairesi Başkanlığı, Ankara, 162 pp., 2007.

Carne, S., Caja, G., Ghirardi, J. J., and Salama, A. A. K.: Long-term performance of visual and electronic identification devices in dairy goats, J. Dairy Sci., 92, 1500-1511, https://doi.org/10.3168/jds.2008-1577, 2009.

Church, J. S., Cook, N. J., and Schaefer, A. L.: Recent applications of infrared thermography for animal welfare and veterinary research: everything from chicks to elephants, Proceedings Inframation, 10, 215-224, 2009.

Düzgün, D. and Or, M. E.: Termal kameraların tıpta veteriner hekimlikte kullanımı, TUBAV Bilim Derg., 2, 468-475, 2009.

Edwards, D. S., Johnston A. M., and Pfeiffer, D. U.: A comparison of commonly used ear tags on the ear damage of sheep, Anim. Welfare, 10, 141-151, 2001.

Grant, C.: Behavioural responses of lambs to common painful husbandry procedures, Appl. Anim. Behav. Sci., 87, 255-273, https://doi.org/10.1016/j.applanim.2004.01.011, 2004.

ISO (International Organization for Standardization): Radiofrequency identification of animals-code structure, ISO 11784: 1996 (E), 2nd Edn., Geneva, Switzerland, 1996a.

ISO (International Organization for Standardization): Radiofrequency identification of animals-technical concept, ISO 11785: 1996 (E), 1st Edn., Geneva, Switzerland, 1996b.

Karakuş, M.: Kuzularda kulak küpesi uygulamasının refah açısından değerlendirilmesi, MSc Thesis, Yuzuncu Yil University, Van, 48 pp., 2016.

Karakus, F., Demir, A. Ö., Akkol, S., Düzgün, A., and Karakus, M.: Performance of electronic and visual ear tags in lambs under extensive conditions in Turkey, Arch. Anim. Breed., 58, 287292, https://doi.org/10.5194/aab-58-287-2015, 2015a.

Karakuş, F., Düzgün, A., Karakuş, M., and Aslan, L.: Can infrared thermography be used to predict ear tags infections in lambs?, Scientific Papers Series D. Anim. Sci., 58, 205-208, 2015 b.

Karakuş, F., Demir, A. Ö., Akkol, S., Düzgün, A., and Karakuş, M.: Readability of electronic and visual ear tags in Hair goat kids, Turkish JAF Sci. Tech., 4, 407-410, 2016.

Karasu, A. and Bakır, B.: Veteriner cerrahide kullanılan dikiş materyalleri, YYU Vet. Fak. Derg., 17, 37-44, 2006.
Kitagaki, M. and Shibuya, K.: Nylon ear tags for individual identification of guinea pigs, Contemp. Top. Lab. Anim. Sci., 43, 16-20, 2004.

Kowalski, L. H., Monteiro, A. L. G., Hentz, F., Prado, O. R., Kulik, C. H., Fernandes, S. R., and da Silva, C. J. A.: Electronic and visual identification devices for adult goats reared in semi-intensive system, Rev. Bras. Zootecn., 43, 100-104, 2014.

Leslie, E., Hernandez-Jover, M., Newman, R., and Holyoake, P.: Assessment of acute pain experienced by piglets from ear tagging, ear notching and intraperitoneal injectable transponders, Appl. Anim. Behav. Sci., 127, 86-95, https://doi.org/10.1016/j.applanim.2010.09.006, 2010.

Martin, G. B.: The "clean, green and ethical" concept in animal production, Agrociencia, 13, 1-7, 2009.

Martin, G. B. and Kadokawa, H.: "Clean, green and ethical" animal production. Case study: reproductive efficiency in small ruminants, J. Reprod. Dev., 52, 145-152, 2006.

Molony, V., Kent, J. E., and McKendrick, I. J.: Validation of a method for assessment of an acute pain in lambs, Appl. Anim. Behav. Sci., 76, 215-238, https://doi.org/10.1016/S01681591(02)00014-X, 2002.

SAS Institute Inc.: SAS/STAT User's Guide: Version 9.3. SAS Institute Inc., Cary, NC, USA, 2005.

Sevgisunar, N. S. and Şahinduran, Ş.: Hayvanlarda akut faz proteinleri, kullanım amaçlarıve klinik önemi, MAKÜ Saglık Bilim. Enst. Derg., 2, 50-72, 2014.

Stewart, M.: Non-invasive measurement of stress and pain in cattle using infrared thermography, $\mathrm{PhD}$ thesis, Massey University, Palmerston North, New Zealand, 165 pp., 2008.

Stewart, M., Webster, J. R., Schaefer, A. L., and Stafford, K. J.: Infrared thermography and heart rate variability for non-invasive assessment of animal welfare, ANZCCART News, 21, 1-4, 2008.

Thomas D. L., Hernandez-Jover, M., Rovai, M., Bishop, M., Caja, G., Berger, Y. M., Taylor, T. A., Bishop, B., Taylor, L., Gottfredson, R. G., Frank, M., Schlapper, R., Bolan, B., and Keough, $\mathrm{W}$.: Variable effectiveness of radio frequency ear tags and rumen boluses for electronic identification of sheep, in: Proceedings of the 52nd Biennial Spooner Sheep Day, Spooner Agricultural Research Station University of Wisconsin-Madison Spooner, Wisconsin, USA, 26 August 2006, 11-21, 2006.

Young, S. K.: The Effect of Predator Presence on the Behavior of Sheep in Pain, M.Sc. thesis, Massey University, Palmerston North, New Zealand, 127 pp., 2006. 